\title{
“Wiraku Suci”: A Children's App for Learning Hygiene Practices
}

\author{
Aznoora Osman ${ }^{1 *}$, Nurul Husniyah Mohd Azman² \\ ${ }^{1,2}$ Faculty of Computer and Mathematical Sciences, \\ Universiti Teknologi MARA Perlis Branch, Arau Campus, 02600 Arau, Perlis, Malaysia \\ Corresponding author:*aznoora@uitm.edu.my \\ Received Date: 20 August 2021 \\ Accepted Date: 4 September 2021 \\ Published Date: 20 September 2021
}

\section{HIGHLIGHTS}

- Personal hygiene care is important to avoid health issues related to cleanliness

- Teaching children about hygiene requires parents to demonstrate clearly and practice it.

- Video clips, pictures with narration, drag and drop games, and pictorial quiz are practical.

- Mobile learning app provides integrated solution to help parents teach effectively.

\begin{abstract}
Hygiene care is a basic human need, but very essential practice that must be taught since childhood. Personal hygiene involves making sure body parts are clean to avoid from health issues caused by poor cleanliness. Parents ultimately bear the responsibility to teach their children about cleanliness, and normally this is done by showing and practising hygiene care themselves. Nevertheless, it is not that easy to educate personal hygiene care to them, especially in the ages of four to six years old, because they are actively playing and exploring their environments. To aid parents, mobile learning app could be employed because hygiene habits can be shown via more engaging ways such as through pictures and video clips of personal hygiene care, simple drag and drop games, and pictorial quiz. In this study, a mobile learning app with game-based approach has been developed by following the software development life cycle Spiral model. During evaluation phase, a heuristic evaluation with five Computer Science lecturers was conducted to examine the usability of the app. Results from the evaluation were used as guidance to refine and improvise the app so that they will be usable and enjoyable for children.
\end{abstract}

Keywords: hygiene care, children, mobile learning app

\section{INTRODUCTION}

Personal hygiene is commonly characterized as body cleanliness and proper personal appearance maintenance which include both body areas and clothes ("Why is personal hygiene important?", 2020). Personal hygiene also means keeping all parts of the external body to be clean and healthy (Ames, 2020). Hygiene care is very important to everyone, but to instill excellent cleanliness habits, it must start from childhood so that everyone can grow into a healthy adult, both physically and mentally. According to the Center for Disease Control (CDC), it is also important for everyone to take care of their hygiene especially during cough or flu seasons because the virus can be easily spreaded. Furthermore, simple hygiene care can aid in protecting everyone from having any health issue (Gonggala, 2015). 
Nevertheless, it is not an easy task for children to take care of their personal hygiene. At the same time, developing good personal hygiene habits is very crucial to the children especially in this COVID-19 pandemic (UNICEF, 2020). It is a big responsibility of the parents to make sure their children to be more careful in whatever they do. This is because during this pandemic, everyone needs to know the importance of personal hygiene to prevent COVID-19 virus by washing hands as frequently as possible with the antibacterial soap and using hand sanitizer especially when going out. They also need to teach their children properly on how to be a person with good hygiene habits. This is challenging especially when training children in the age of four to six year old because at this age range, children are usually active and want to explore more of their physical surrounding. They enjoy playing outside with friends and venture into new things. Hence, it is vital for every parent to be more focused on their children's cleanliness habits in this new norm.

Therefore, the learning app focuses on teaching children about personal hygiene care. Personal hygiene includes the ethics of hand washing before and after eating as well as after using the toilet, washing hands with soap for at least 20 seconds, using the tissue to cover the mouth and nose when sneezing or coughing, and disposing used tissues immediately before washing their hands. It is hoped that with enough exposure about personal cleanliness, children will practice them into adulthood.

\section{LITERATURE REVIEW}

\section{Game-based Learning}

According to Pierce (2015), a survey of education in the game-based learning category shows that most of the developers are targeting to develop games for young children who are aged five years old and under. It is found that the percentage made for age five and under is $60 \%$, for age six to eight is $29 \%$, and for age nine to eleven is $11 \%$. Game-based Learning (GBL) is about learning that can boost the children to study and learn new things while playing by having an exciting learning process (Al-Azawi, Al-Faliti \& AlBlushi, 2016). Morever, game-based learning can make the children improve their learning motivation due to the combination of game and course compared to a traditional learning process that is boring for them (Al-Azawi et al., 2016).

The learning process based on digital games education can stimulate children's curiosity in such a way for them to solve problems by creating attractiveness in the visual sides, which in turn can increase children's satisfaction (Behnamnia et al., 2020). Next, game-based learning also has various types of cognitive loads than non-game-based learning. In a game-based learning environment, there are interactive features which are two-dimensional (2D) and three-dimensional (3D) spaces to attract the learners so that they will explore more about the games (Chang, Liang, Chou \& Lin, 2017). In addition, game-based learning can make the children focus on learning, especially when they gain curiosity and wonder about something new they have found (Sawyer, 2017).

\section{Mobile Application}

The mobile device market has been growing rapidly, and new mobile applications are being developed and shipped on a routine basis (Holl \& Elberzhager, 2019). Nowadays, mobile devices such as smartphones and tablets have exceeded the use of personal computers in our daily lives (Chen, 2018). Hence, mobile learning is a recent innovation that triggers the interest of many learners, educators, marketers, and 
designers (Chen, 2018). It has been identified as a potential educational approach which the mobile technology can be used to extend learning activities and integrate with various emerging technologies such as virtual reality and robots (Chung, Hwang \& Lai, 2019).

Young people also spend a lot of their free time on their smartphones and playing games. The concept of playing a mobile game assumes that the player is doing so voluntarily, but not solely for leisure activities; it can also include a desire to learn a skill, connect with other game players for social interaction, and spend some time in a chosen assessment unit.

\section{Game Design, Elements and Guidelines}

The important aspect when designing games includes imagination, fantasy, and experience gained (Anugerah \& Budiyanto, 2017). Designers can apply design guideline aimed at young children that corresponds to Dix et al.'s usability principles, Nielsen's heuristics, Shneiderman's eight golden rules, or Preece, et al.'s usability principles (Gelderblom \& Kotzé, 2008). Furthermore, a design that focuses on learning games involving children's perspectives needs a comprehensive design process to assist them throughout their activities (Ismail, Ibrahim \& Yaacob, 2018).

Designing a game for children needs to consider their dual character of overlapping which is in physical and digital dimension where for the digital, it involves things such as the players will interact with a character to generate information or to engage in problem-solving activities like solving puzzles (Avouris, Sintoris, \& Yiannoutsou, 2018). Before designing a game, a developer needs to study about user requirements by using User-Centered Design (UCD), User Experience (UX), Human-Centered Design (HCD), and others (Ismail et al., 2018).

\section{METHODOLOGY}

The study adopted the System Development Life Cycle (SDLC) Spiral model in developing the learning app. The Spiral model shows the processes that define the development cycle of its stages and tasks. In this model, there are four major phases involved which are design prototyping, playtesting, evaluation, and risk analysis phases (Aslan \& Balci, 2015). Each phase has its own task that must be carried out. Nevertheless, for this study, the risk analysis phase was excluded because this is just a prototype that is not yet intended for commercialization and mass use.

Game idea specification phase involves gathered information, components used in the project, identified projects, and the games design process. There are a few components that are suitable for young children that have been employed in this project such as audio, colourful images, text style, and interesting interface. To gather the information, previous researchers' works related to the theme of game-based learning, hygiene, young children, and mobile-based applications have been examined. As a result, the scope of learning module were narrowed into contents like hygine practices like washing hands, using hand sanitiser, brushing teeth, wearing face mask, coughing and sneezing etiquette, and personal hygiene tools. These can be delivered in two techniques which are (1) in the form of video clips to demonstrate actual actions, and (2) pictures with caption and voice description about the hygiene practice. Figure 1 depicts ideas for presenting the learning contents. 


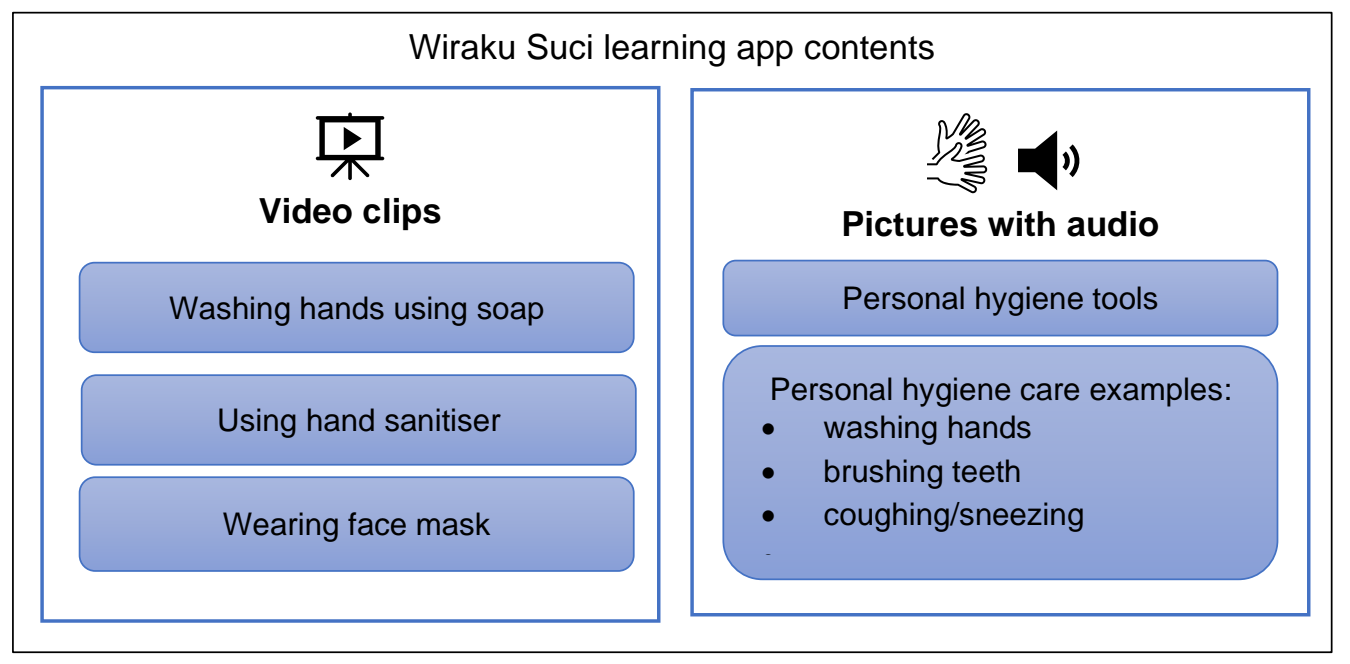

Figure 1: Learning Contents of Wiraku Suci

The second phase is the design prototype phase where prototype of the end product was designed. Wiraku Suci was designed by using the principles and guidelines of the Nielsen and Molich User Interface (UI) guidelines and HCI principles. The principles consist of several elements such as the user interface, functionality, theme, navigation, and appearance for the app. Audio, graphical, and video assets were also collected at this phase as a preparation before combining them during development. The graphics and videos were created so that it could match suggestions by Anugerah \& Budiyanto (2017) where imagination and fantasy should be considered when designing for children. A sitemap to illustrate the navigation and screen flow was also created.

The design prototyping phase also consists of few tasks to integrates game elements, game principles, and guidelines in the user interface. To develop a game for children, game elements is also one of the design techniques that must be known by every developer to create a good game. Before identifying which elements that can be put in that game, a developer needs to know the User Experience (UX) as it plays the critical part which users need to identify their feelings when interacting with some products either it is good or not (Nagalingam \& Ibrahim, 2017). Game elements also can be described as a collection of audio, video game components, images, styles, and practices in the game (Ferreira-Brito et al., 2019).

The learning app consists of learning module that is presented using video clips and pictures with caption and voice description. Since Avouris et al. (2018) recommended that game should be designed with problem solving activities, the game module consists of a drag and drop game about hygiene tools, and a simple pictorial quiz about correct hygiene practices. Problem solving activity in the drag and drop game would require user to drag image of every hygiene tool to its correct silhouette. Pictorial quiz requires user to choose correct answer from two options that are presented using pictures. The quiz question is presented using text and audio, which means user can see the question while also listening to its voice narration. Using audio is especially useful since young children might not be able to read yet. 
To instil sense of achievement, when a correct picture is chosen as the answer, a smiling emoticon showing thumbs-up would appear, whereas if the answer is incorrect, a cross icon in red color would appear. Nevertheless, the main aim of the quiz is not to gauge score and performance; however, it provides opportunity for children to recall hygiene lessons that they have explored in learning module. Failure to choose the correct answer will allow children to learn from their mistakes and restart, a game element that is recommended by Kiang (2014). This game design is also in line with recommendation by Anugerah \& Budiyanto (2017) where game-based learning system should assists students in learning via fun way, especially when the materials involve educational activity.

After finalising the design, the development started. Unity 3D software was used as the development tool and embedded in C\# to integrate the interface of the application, while Firebase was employed to store the user data. Unity 3D version 2019.2.14f1 was used to develop the scenes in Wiraku Suci apps as it can support Android software development kit (SDK) tools. It enabled creation of various animations which would be attractive and enjoyable to children. Adobe Photoshop CS6 was used for editing image such as to create background image and remove background for a few images that were used in the app, for instance images of hygiene tools. Adobe Premiere Pro CS6 was used in this project for editing video clips. Voice recorder from laptop and Vivo S1 smartphones was used in order to record voices for audio. These media assets were then imported into Unity 3D to be embedded into the scenes. Firebase software was used to stored data in order to perform create, read, update and delete (CRUD) functions. This app used firebase authentication to record user login data.

The playtesting phase is the third phase where the completed app was tested by the developer. The purpose was to discover design flaws. The learning module and game module were tested to confirm that both could function as intended, and would respond correctly to every input by the user. Navigation from main screen to all the other screens, and vice versa were also examined to ensure smooth experience, without dead link or orphaned page.

\section{Samples of Screens}

This section describes Wiraku Suci app screen interfaces. Figure 2 depicts the start page where user can log in or sign up.

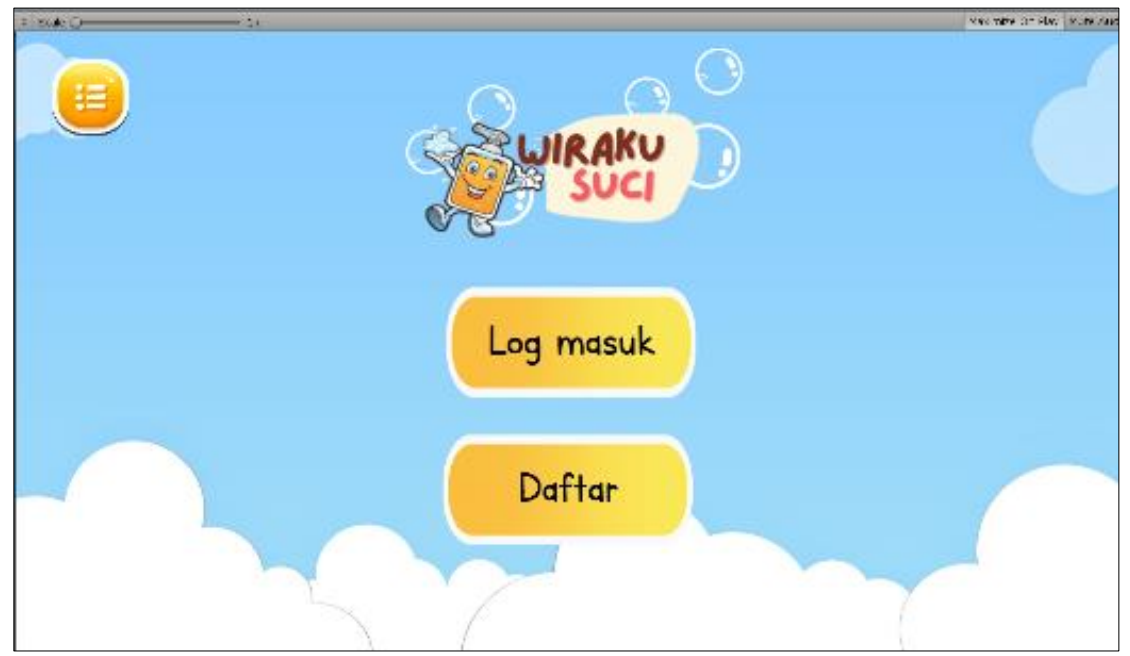

Figure 2: Start Page 
Figure 3 illustrates the main menu. Here, user can choose either to explore the learning module (named Mari Belajar), or proceed to game module (named Permainan).

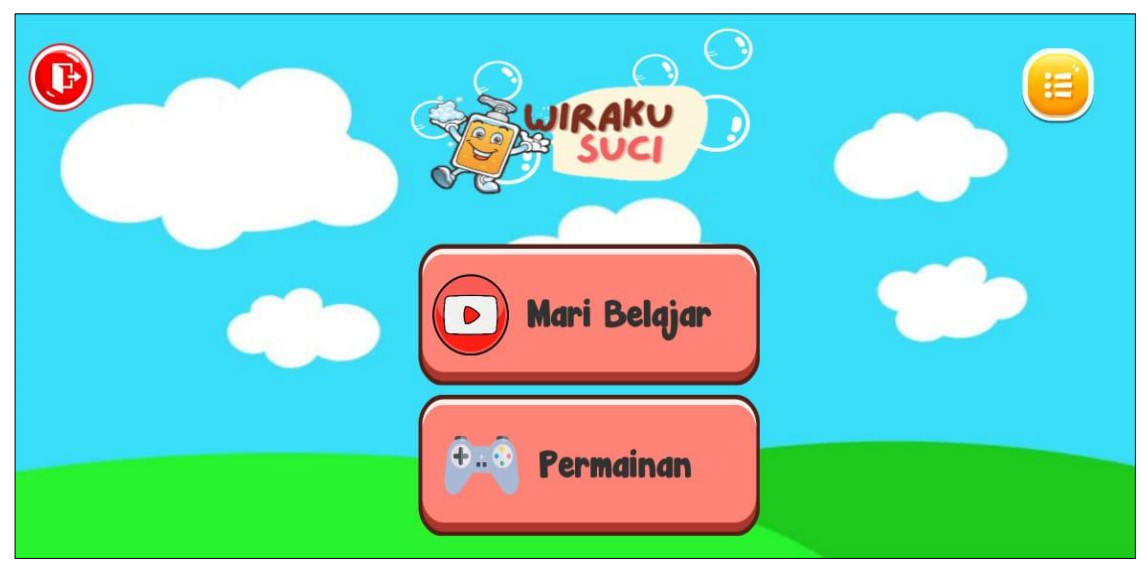

Figure 3: Main Menu

When button "Mari Belajar" is clicked, the menu for learning module which consists of five lessons will be displayed. This screen is shown in Figure 4.

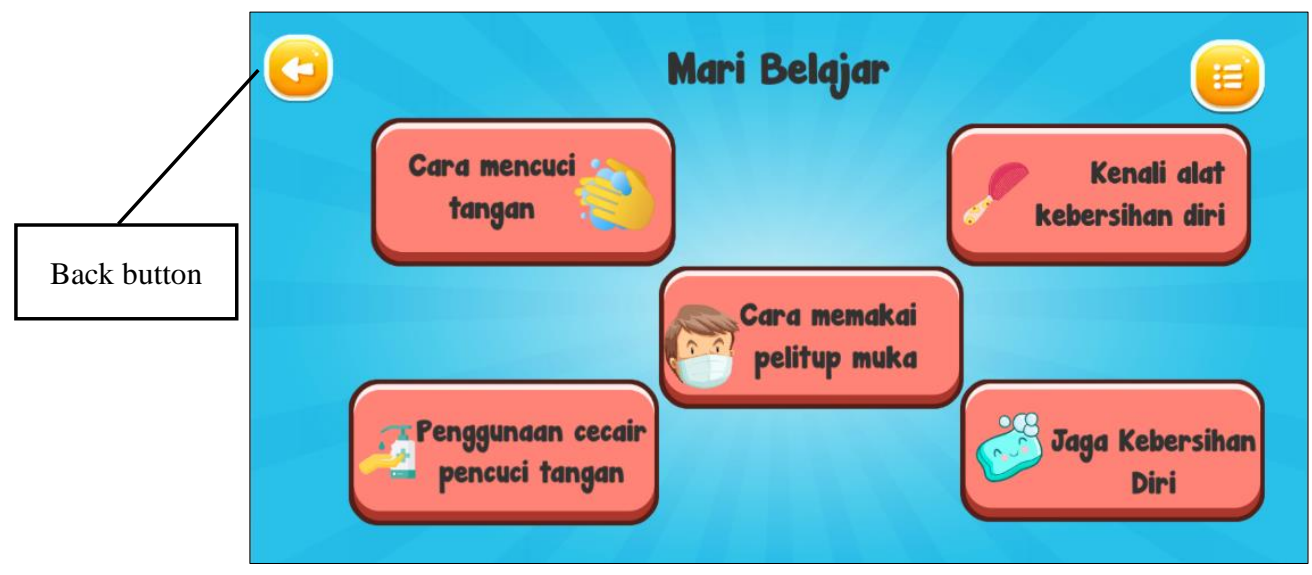

Figure 4: Five Lessons in Learning Module

In order to exit from the learning module, the Back button should be clicked. If the button labeled "Cara mencuci tangan" is clicked, a video clip will be played, as depicted in Figure 5. It is equipped with controller to allow freedom to pause, restart or stop the video. Menu for game module, and drag and drop game about hygiene tools are shown in Figure 6 and Figure 7 respectively. 


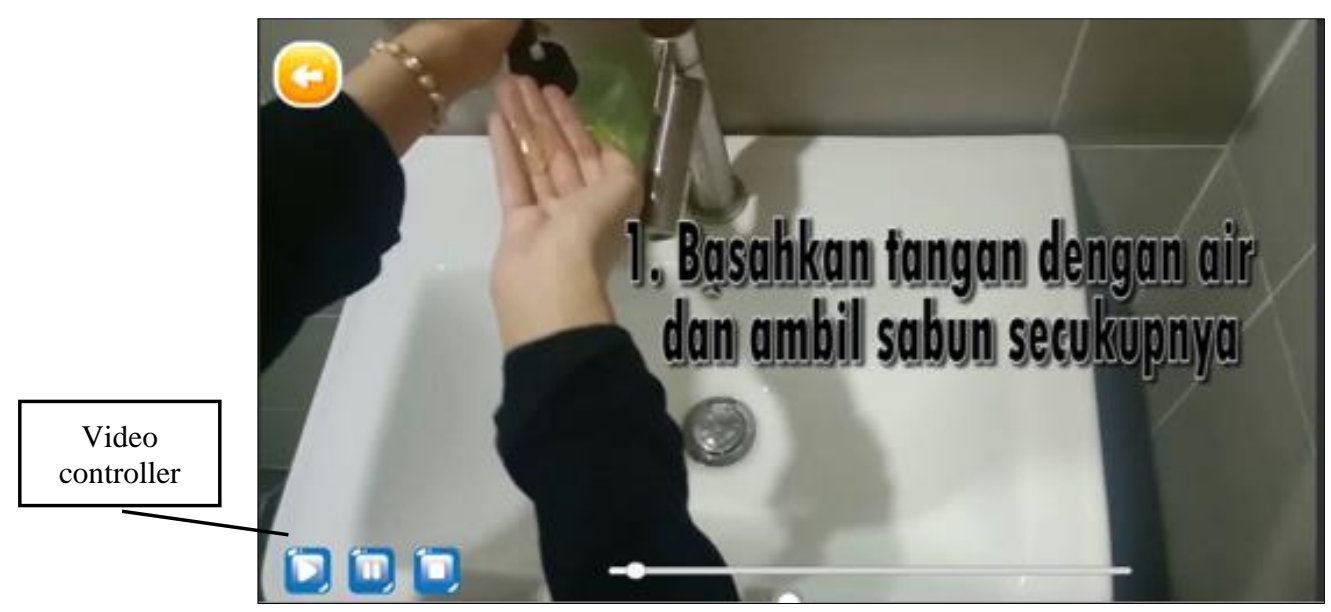

Figure 5 : Video Clip of Hands Washing

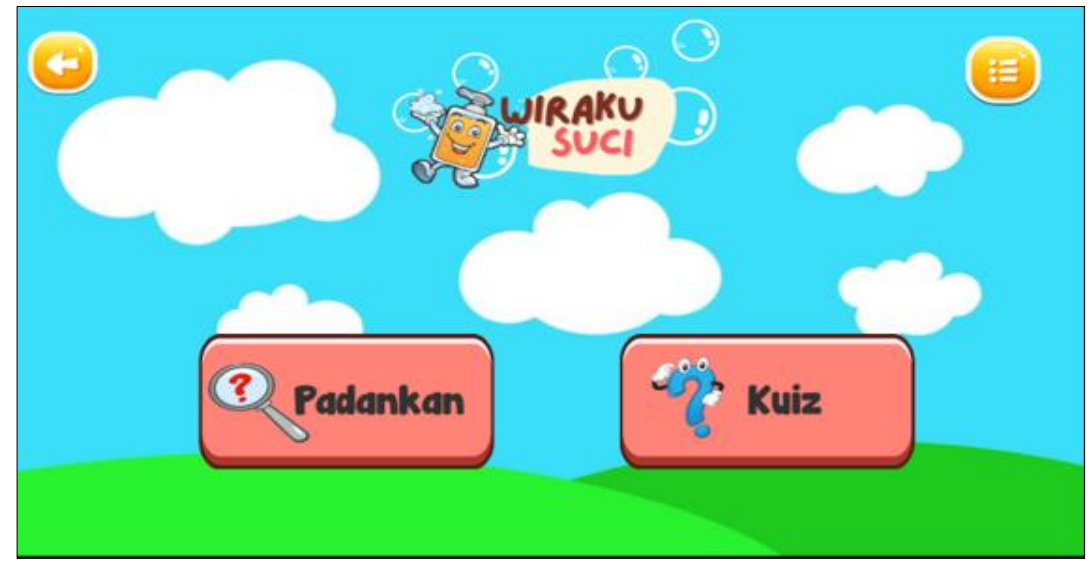

Figure 6 : Menu in Game Module

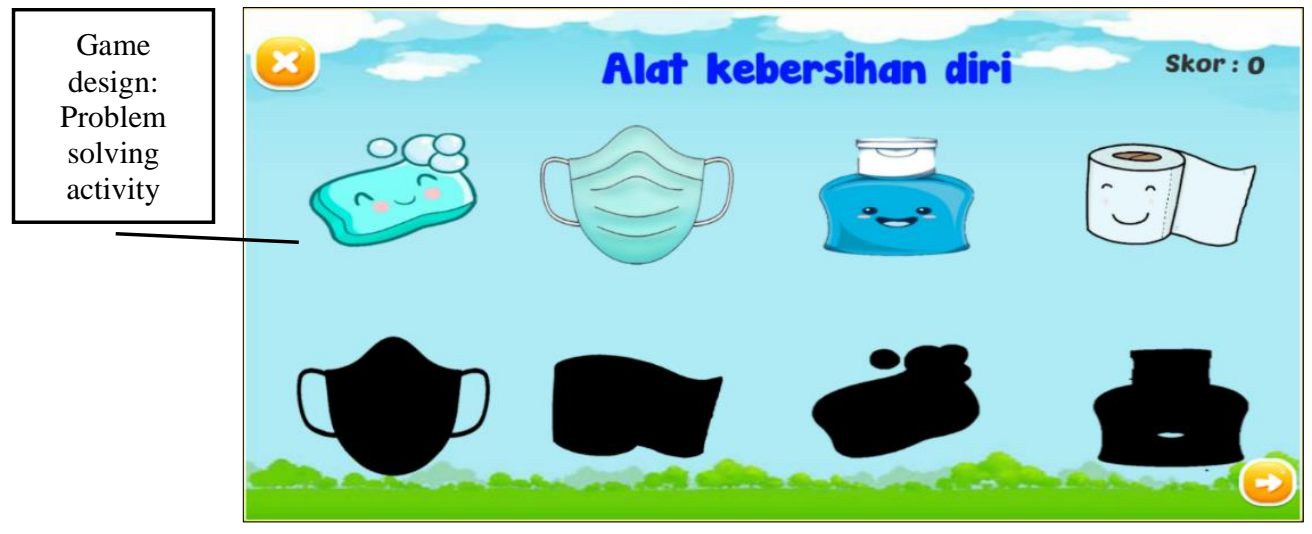

Figure 7 : Drag and Drop Game - Hygiene Tools

Figure 8 illustrates the pictorial quiz,with thumbs up emoticon being displayed after correct answer is chosen, which in this case, tangan. 


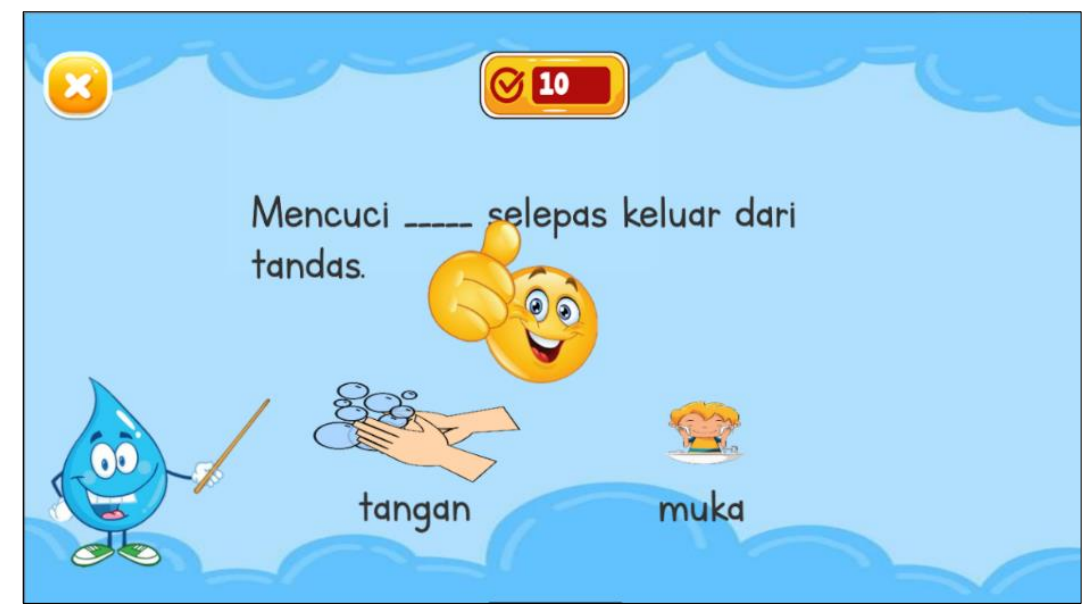

Figure 8 : Pictorial Quiz with Thumbs Up Emoticon

\section{Evaluation}

Usability evaluation is an important evaluation that is recommended in order to ensure a better level of product usability (Vee Senap \& Ibrahim, 2019), and to ensure success of educational game (Fatta et al. , 2018). The evaluation on Wiraku Suci app was administered to gain feedback from experts in the field of learning and mobile application. The evaluation criteria was based on four dimension of heuristics evaluation component for mobile educational games which are game usability, game play, mobility, and learning content. Additionally, experts had to provide suggestions or comments for improvement of the app. The evaluation was conducted virtually by sharing video containing project description and app demonstration via WhatsApp and Google Drive. With a duration of nine minutes, the video of app demonstration provided brief explanation of the problem statement, proposed solutions and displayed thoroughly every screen in the learning app.

Experts were instructed to watch the video and observe the overall functions, then filled up the evaluation instrument. There were 12 questions which can be answered by choosing only one feedback towards every usability statement using Likert scale that was represented with number, either Strongly Disagree (1), Strongly Agree (2), Neutral (3), Agree (4), and Strongly Agree (5).

\section{FINDINGS AND DISCUSSIONS}

This section discusses generally the findings from usability heuristic evaluation. The learning app can be deemed as highly usable because with the mean score of 4.6 in navigation, 4.2 in feedback, 3.6 in memorising and 4.4 in freedom to leave. Mobility dimension received mean score of 4.2. This is because Wiraku Suci app can be loaded into the screen immediately and children can start playing by simply clicking on the provided button. Furthermore, there are five buttons that can be clicked in the Mari Belajar module, namely 'Cara mencuci tangan', 'Cara menggunakan cecair pencuci tangan', 'Cara memakai pelitup muka', 'Kenali alat kebersihan diri', and 'Jaga kebersihan diri'. The freedom to choose topic they would like to learn, rather than being presented with continuous lesson, is considered empowering for young children, and promotes sense of independence. With regards to learning content, it received mean score of 4.0, which means experts agreed that the content can be learned easily. 
Next, statement "It provides learning content about how to take care of personal hygiene" received mean score of 3.6, which is considered low. This is unsurprising because in the feedback section, experts commented that some video contents should be accompanied with voice narration and captions to enhance understanding while watching it, and recommended to add learning contents that match with the questions in pictorial quiz. Therefore, refinements were made so that it would be a practical and enjoyable learning app for young children.

\section{CONCLUSION AND RECOMMENDATIONS}

From the activities in development, playtesting and evaluation phases, three advantages of the learning app have been identified, (1) children can learn from modelling, where actual practices of personal hygiene are demonstrated via video clip, (2) children are able to know the tools that can be used daily in order to take care of their personal hygiene, and (3) Children have freedom to learn and play repeatedly, thus could eventually deepen their understanding about personal hygiene care. Future work to improve its features and functionalities would be to add more video clips that teach about various other hygiene practices, and to provide score board for children to see their performance at the end of the game.

\section{ACKNOWLEDGMENTS}

The researchers would like to record a sincere gratitude to all expert evaluators who participated in the usability heuristic evaluation.

\section{REFERENCES}

Al Fatta, H., Maksom, Z., \& Zakaria, M. H. (2018). Systematic literature review on usability evaluation model of educational games: Playability, pedagogy, and mobility aspects. Journal of Theoretical and Applied Information Technology, 96(14), 4677-4689.

Ames, H. (2020, May 20). Why is personal hygiene important? Retrieved November 10, 2020, from Medicalnewstoday.com website: https://www.medicalnewstoday.com/articles/personal-hygiene

Anugerah, Y., \& Budiyanto, C. (2017). The Design of Children Educational Game Interface: Review of the Literature. 158(Ictte), 859-867. https://doi.org/10.2991/ictte-17.2017.87

Aslan, S., \& Balci, O. (2015). GAMED: Digital educational game development methodology. Simulation, 91(4), 307-319. https://doi.org/10.1177/0037549715572673

Avouris, N., Sintoris, C., \& Yiannoutsou, N. (2018, June). Design guidelines for location-based mobile games for learning. In Proceedings of the 17th ACM Conference on Interaction Design and Children (pp. 741-744).

Behnamnia, N., Kamsin, A., Ismail, M. A. B., \& Hayati, A. (2020). The effective components of creativity in digital game-based learning among young children: A case study. Children and Youth Services Review, 116(June), 105227. https://doi.org/10.1016/j.childyouth.2020.105227. 
Chang, C., Liang, C., Chou, P., \& Lin, G. (2017). Computers in Human Behavior Is game-based learning better in fl ow experience and various types of cognitive load than non-game-based learning? Perspective from multimedia and media richness. Computers in Human Behavior, 71, 218-227. https://doi.org/10.1016/j.chb.2017.01.031

Chen, C. P. (2018). Understanding mobile English-learning gaming adopters in the self-learning market: The Uses and Gratification Expectancy Model. Computers and Education, 126(April 2018), 217230. https://doi.org/10.1016/j.compedu.2018.07.015

Chung, C. J., Hwang, G. J., \& Lai, C. L. (2019). A review of experimental mobile learning research in 2010-2016 based on the activity theory framework. Computers and Education, 129, 1-13. https://doi.org/10.1016/j.compedu.2018.10.010

Cook, K. L., \& Bush, S. B. (2018). Design Thinking in Integrated STEAM Learning: Surveying the Landscape and Exploring Exemplars in Elementary Grades. School Science and Mathematics, 118(3), 93-103. https://doi.org/http://dx.doi.org/10.1111/ssm.12268

Ferreira, S. M., Gouin-Vallerand, C., \& Hotte, R. (2016). Game based learning: A case study on designing an educational game for children in developing countries. 2016 8th International Conference on Games and Virtual Worlds for Serious Applications, VS-Games 2016. https://doi.org/10.1109/VSGAMES.2016.7590350

Gelderblom, H., \& Kotzé, P. (2008). Designing technology for young children: What we can learn from theories of cognitive development. ACM International Conference Proceeding Series, 338(October), 66-75. https://doi.org/10.1145/1456659.1456668

Gongala, S. (2015, September 16). Personal Hygiene For Kids: Importance And Habits To Teach. Retrieved December 5, 2020, from MomJunction website: https://www.momjunction.com/articles/personalhygiene-tips-for-kids_00372473/

Holl, K., \& Elberzhager, F. (2019). Mobile Application Quality Assurance. In Advances in Computers (1st ed., Vol. 112). Elsevier Inc. https://doi.org/10.1016/bs.adcom.2017.12.001

Ismail, R., Ibrahim, R., \& Yaacob, S. (2018). Human computer interaction and game design process for children. Open International Journal of Informatics (OIJI), 6(2), 43-52.

Kiang, D. (2014, Oct 14). Using gaming principles to engage students.Edutopia.

https://www.edutopia.org/blog/using-gaming-principles-engage-students-douglas-kiang

Nagalingam, V., Ibrahim, R., \& Yusoff, R. C. M. (2020). EDUGXQ: User Experience Instrument for Educational Games' Evaluation. International Journal of Advanced Computer Science and Applications, 11(1).

Pierce, N. (2015, February 9). Game-based Learning for Early Childhood (Part 1) | Learnovate. Retrieved December 2020, from Learnovate website: https://www.learnovatecentre.org/gbl_early_childhood_pt1/

Sawyer, R. (2017). Balancing learning and engagement in game-based learning environments with multiobjective reinforcement learning. Lecture Notes in Computer Science (Including Subseries Lecture 
Notes in Artificial Intelligence and Lecture Notes in Bioinformatics), 10331 LNAI, 323-334. https://doi.org/10.1007/978-3-319-61425-0_27

UNICEF. (2020, September 17). Everything you need to know about washing your hands to protect against coronavirus (COVID-19). https://www.unicef.org/coronavirus/everything-you-need-know-aboutwashing-your-hands-protect-against-coronavirus-covid-19

Vee Senap, N. M., \& Ibrahim, R. (2019). A review of heuristics evaluation component for mobile educational games. Procedia Computer Science, 161(2), 1028-1035. https://doi.org/10.1016/j.procs.2019.11.213

"Why is personal hygiene important?". (2020). Medicalnewstoday. Retrieved Jan 5, 2020 from https://www.medicalnewstoday.com/articles/personal-hygiene

World Health Organization: WHO. (2020, October 15). WHO and Disney Junior's "Doc McStuffins" team up to remind young kids to wash their hands. Retrieved December 13, 2020, from Who.int website: https://www.who.int/news-room/feature-stories/detail/who-and-disney-junior-s-doc-mcstuffinsteam-up-to-remind-young-kids-to-wash-their-hands 